\title{
Assessment of Cardiovascular Changes among Indoor and Outdoor Cleaners in a Tertiary Institution in Delta State, South-South Nigeria
}

\author{
${ }^{* 1 O V U A K P O R A Y E, ~ S I ; ~}{ }^{1}$ OJIEH, AE; ${ }^{2}$ OKUMAGBA, MT \\ ${ }^{*}$ Department of Human Physiology, Faculty of Basic Medical Sciences, Delta State University, Abraka \\ ${ }^{2}$ Department of Community Medicine, Faculty of Clinical Medicine, Delta State University, Abraka \\ *Corresponding Author Email: simonovuakpo2006@yahoo.com
}

\begin{abstract}
This study is aimed at assessing cardiovascular changes amongst indoor and outdoor cleaners in Delta State University, Abraka. A total of one hundred (100) cleaners were randomly selected for the study, comprising of fifty (50) indoor and fifty (50) outdoor cleaners. Data were collected and the digital sphygmomanometerwas used to measure blood pressure and pulse rate of subjects. Results obtained ranged from $93 / 73 \mathrm{mmHg}-177 / 102 \mathrm{mmHg}, 62-102 \mathrm{beats} / \mathrm{min}$ and $85 / 50-139 / 90 \mathrm{mmHg}, 60-107 \mathrm{beats} / \mathrm{min}$ for indoor and outdoor cleaners respectively. The result showed that the mean blood pressure was higher in indoor cleaner than outdoor cleaners and the mean pulse rate of outdoor cleaners was higher than that of indoor. Also, age was positively correlated with pulse rate and systolic blood pressure while the duration of work per day was correlated negatively with blood pressure and pulse rate. The study has established that blood pressure was higher among indoor cleaner than outdoor cleaner, while pulse rate was higher among outdoor cleaner than indoor cleaners. The study has also strengthened the need for cleaners to put on protective devices to reduce exposure to air pollution and encourage cleaners to undergo regular medical check.
\end{abstract}

DOI: https://dx.doi.org/10.4314/jasem.v24i2.8

Copyright: Copyright (C) 2020 Ovuakporaye et al. This is an open access article distributed under the Creative Commons Attribution License (CCL), which permits unrestricted use, distribution, and reproduction in any medium, provided the original work is properly cited.

Dates: Received: 16 November 2019; Revised: 11 January 2020; Accepted: 22 February 2020

Keywords: Assessment, cardiovascular changes, indoor and outdoor cleaners

Individuals prune to high occupational physical activity (OPA) often come down with an increase rate of cardiovascular morbidity (Li et al., 2013). Cleaners are vulnerable to high OPA encompassing working while walkingand standing combined with recurrent static working postures (Korshoj et al., 2013). A reason for the high incidence of cardiovascular disease among cleaners could be as a result of the combination of high occupational physical activity and a low cardiopulmonary fitness, generating a high relative aerobic workload (Zoller et al., 2012). Population in developed nations are spending their time in various indoor and outdoor environments (Farrow et al., 1997). According to WHO 2004, Pollution is any addition of matter or energy that degrades the environment for humans and other organisms. In 2010, air pollution led to 7 million premature deaths worldwide, with similar contributions made by indoor and outdoor air pollution (Lelieveld, 2015).As cleaners generally have low cardiopulmonary fitness and high OPA, they are exposed to moderate to high aerobic workloads throughout their working period (Karlqvist et al., 2003). Long-term exposure of moderate to high relative aerobic workloads could lead to heighten risk of cardiovascular disease due to the proposed dangerous stress on the arterial endothelia (Krause et al., 2015). In addition, cleaners are exposed to various pathogenic agents such as bacteria, viruses and moulds which are released during the cleaning process. These pathogenic organisms can cause infections and diseases which may eventually lead to impairment of pulmonary and cardiovascular functions. This study determines changes in cardiovascular parameters among indoor and outdoor cleaners in Delta State University, Abraka by specifically assessing the changes in blood pressure and pulse rate.

\section{MATERIALS AND METHODS}

Research Design: The current research is a descriptive longitudinal study conducted among indoor and outdoor cleaners of Delta State University Abrakato determine changes in their blood pressure and pulse rate. Subjects between the ages of 20-50 were considered for the study.

Sample Size: 100 subjects comprising 50 indoor cleaners and 50 outdoor cleaners were considered for the study.

Selection Criteria

Inclusion Criteria: Subjects between 20-50 years

Subjects available on the days of selection

Exclusion Criteria

*Corresponding Author Email: simonovuakpo2006@yahoo.com 
Subjects below 20 years and those above 50 years were not selected

Subjects absent on the day of selection

Subjects with other comorbidities like cardiopulmonary diseases, cigarette smokers

Sampling Technique: The 100 subjects used for the study were selected using the simple random sampling technique.

Data Collection: Data were collected using wellstructured questionnaire to obtain social demographic data and a digital sphygmomanometer to measure the blood pressures as well as pulse rates of subjects in sitting position. These measurements were taken two times and the mean values calculated and recorded.

Data Analysis: Data was analyzed with the aid of the SPSS software and were presented in tables, graphs and expressed in percentages were appropriate. T-test statistical tool was used to determine the significant difference between variables and values of $p<0.05$ were said to be statistically significant.

Ethical Approval: Prior to commencement of the study, approval was sought from the research and ethical committee of the Faculty of Basic Medical Sciences Delta State University Abraka (REC/FBMS/DELSU/19/61).

\section{RESULTS AND DISCUSSION}

Descriptive Statistics of Subjects: 100 cleaners comprising 64 female cleaners and 36 male cleaners participated in the study. 50 of outdoor cleaners and 50 indoor cleaners were selected. The mean age of all the subjects was $39.76 \pm 8.0$. Table 1 summarizes the descriptive statistics of indoor cleaners, outdoor cleaners and all cleaners.

Table 1: Relationship between Variables

\begin{tabular}{|l|l|l|l|l|l|l|}
\hline \multirow{2}{*}{$\begin{array}{l}\text { Descriptive } \\
\text { Variables }\end{array}$} & \multicolumn{2}{|l|}{ All Subjects } & \multicolumn{2}{l|}{ Indoor cleaners } & \multicolumn{2}{l|}{ Outdoor cleaners } \\
\cline { 2 - 7 } & N & Mean \pm SD & N & Mean \pm SD & N & Mean \pm SD \\
\hline Age(Years) & 100 & $39.76 \pm 8.0$ & 50 & $40.32 \pm 8.57$ & 50 & $39.2 \pm 7.47$ \\
\hline Systolic BP (mmHg) & & $116 \pm 16.29$ & & $119.14 \pm 17.69$ & & $113.72 \pm 14.42$ \\
\hline DiastolicBP (mmHg) & & $75.21 \pm 11.06$ & & $76.58 \pm 11.45$ & & $73.84 \pm 11.72$ \\
\hline Pulse Rate (B/min) & & $81.14 \pm 11.61$ & & $77.86 \pm 10.41$ & & $84.42 \pm 11.92$ \\
\hline Duration (Years) & & $3.32 \pm 1.17$ & & $3.30 \pm 1.12$ & & $3.34 \pm 1.23$ \\
\hline
\end{tabular}

All relationships was not statistically significant, age was positively correlated with systolic BP $(r=0.04, p>0.05)$ and Pulse rate $(r=0.08$, $p>0.05)$ but negatively correlated with diastolic $B P(r=-0.09, p>0.05)$.

This means that pulse rate increases with age. Similar relationship was observed for duration of years as a cleaner but all were not statistically significant. Working hours per day was negatively correlated with blood pressures and pulse rate but relationship was also not statistically significant.

As shown in Fig. 1A, the mean systolic blood pressure was higher in indoor cleaners than outdoor cleaners. Ttest analysis showed that mean difference between the two types of cleaners was significant. Blood pressure in indoor cleaners was higher than outdoor cleaners. Similar to the observation in Fig. 1A, mean diastolic blood pressure is higher in indoor cleaners than in outdoor cleaners (Fig. 1B) but mean difference was not statistically significant ( $\mathrm{p}$ value $>0.05$ ). Contrary to previous observations, mean pulse rate of outdoor cleaners was higher than that of indoor cleaners. The mean difference between the two type of workers was highly significant $(\mathrm{p}<0.01)$ with t-test analysis. Cleaners are vulnerable to high Occupational Physical Activity (OPA) consisting of working while being at one's feet (standing, walking) combined with frequent static working postures especially using the upper extremities (pushing/pulling the chart/mopping the floor) (Korshoj et al., 2013). Cleaners are prune to various pathogenic agents such as bacteria, viruses as well as moulds which are released during the cleaning process. These pathogenic organisms can cause infections and diseases which can cause impairment of pulmonary and cardiovascular functions. Air pollution with particulate matter (PM) has been found to be a major threat to human health. In 2010, air pollution contributed to seven million premature mortality globally, with similar contributions made by indoor and outdoor air pollution (Lelieveld, 2015). Indoor air pollution has been reported to be more heterogeneous, with wide variations in pollutants and sources between countries. In this study, the mean blood pressure in indoor cleaners was higher than in outdoor cleaners but mean difference was only significant with systolic blood pressure $(\mathrm{p}<0.05)$ but not statistically significant with diastolic blood pressure $(\mathrm{p}>0.05)$. This higher value in indoor cleaners could be attributed to the observation during cleaning process in which the accumulated dust and concentration of pollutants indoors was denser than dust accumulation outside which was easily dispersed and diffused into the open air. Indoor cleaners breathe in this air till completion of cleaning process inside these rooms, halls, classrooms and offices. Korshoj et al. (2013) reported that the degree of exposure and concentration of 
pollutants in the air had significant effects on cardiovascular and pulmonary parameters. In their study, concentration of air pollution was positively correlated with blood pressure. This is in line with several studies that have reported association between long-term exposure to densely polluted air with cardiopulmonary diseases (Hook et al., 2013; Miller et al., 2007).

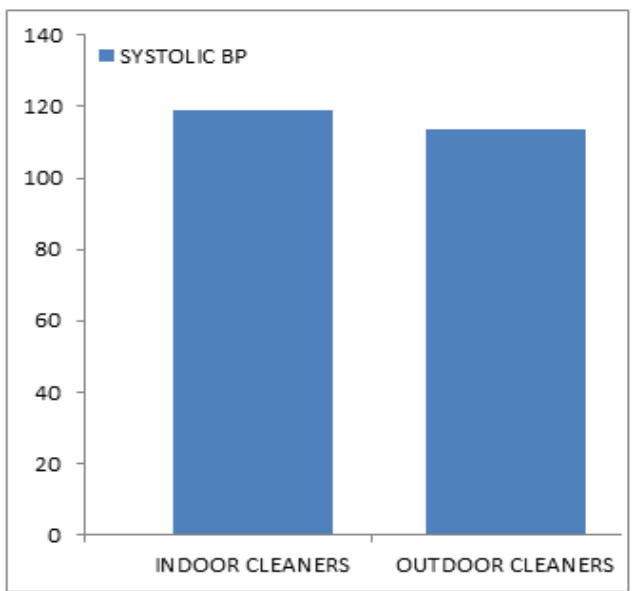

Fig 1A Comparison of Cardiovascular Parameters between Indoor and Outdoor Cleaners

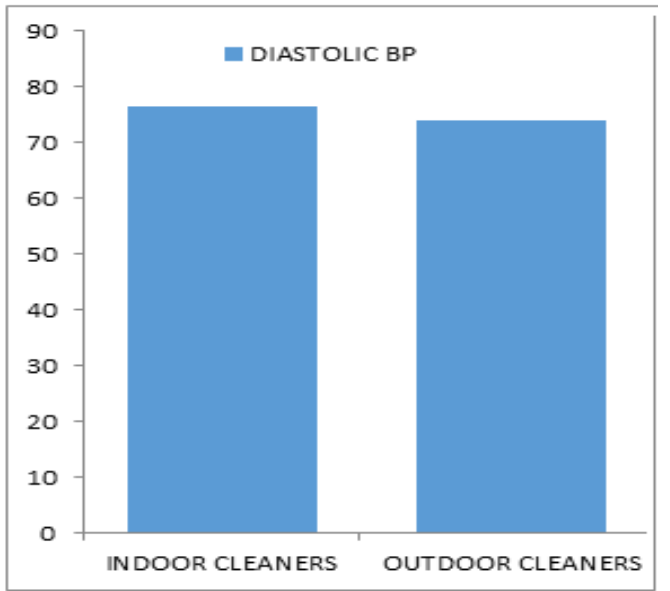

Fig.1B Diagram showing the comparison between the mean diastolic BP of indoor and outdoor cleaners $(t=1.18, p=0.12, t$ critical $=1.66$ )

Contrary to the previous observation, the mean pulse rate was significantly higher in outdoor cleaners than in indoor cleaner although pulse rate was negatively correlated with blood pressure amongst all subjects. Groups with higher blood pressures had lower pulse rates while those. The possible reason for this observation is not clear but it could be due to a combination of factors such as gender and body mass index of the cleaners. with lower blood pressure had higher pulse rates.

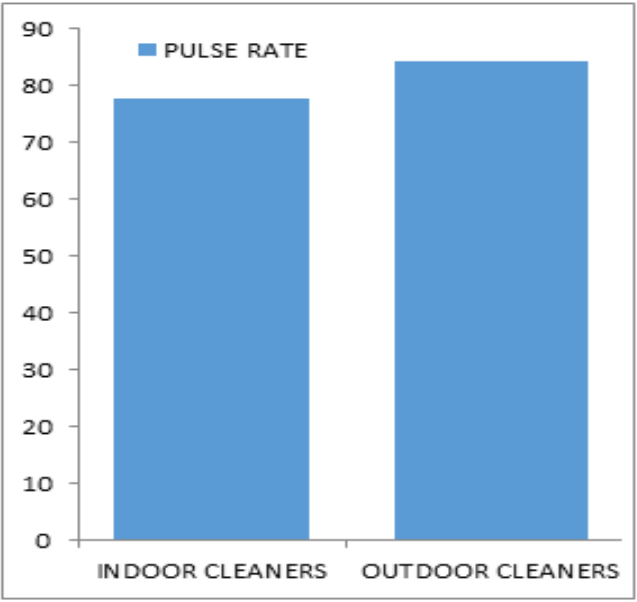

Fig. 2 Diagram showing the comparison between the pulse rate of indoor and outdoor cleaners $(\mathrm{t}=-2.93, \mathrm{p}=0.002$, $\mathrm{t}$-critical $=1.66)$.

A contrary finding was observed by Diego et al. (2017) which found a positive relationship between blood pressure and pulse rate although the relationship was not statistically significant. Duration of years as a cleaner was positively correlated with blood pressures. This signifies that blood pressure of cleaners increases with duration of years from time of employment as a cleaner. This finding also strengthens the relationship between duration of exposure to dust and other air pollutants during cleaning process. A long-term exposure study has investigated the cardiovascular effects of air pollution after annual variations in pollutant concentration (Boudrel et al., 2017). The study extrapolated the extent of individual exposure to air pollution, taking into consideration background pollutant concentrations or road traffic exposure as this was not the case in this university community with good planning and layout of internal roads. The study reported greater impact of air pollution on cardiovascular parameters of cleaners with longer duration of exposure.

Conclusion: The study has demonstrated that blood pressure was higher among indoor cleaners when compared with outdoor cleaners. On the other hand, Pulse rate was higher amongst outdoor cleaners than indoor cleaners. It is our recommendation that Indoor cleaners should ensure that all windows and doors are widely opened for proper ventilation and for faster diffusion of polluted air into the outside environment when cleaning andcleaners are encouraged to put on appropriate protective wears to reduce exposure to air pollutants.

Acknowledgement: The authors wishes to appreciate our research assistant Agboro Ruth for her effort in the 
course of data collection. However, this research was funded by the authors.

\section{REFERENCES}

Bourdrel T, Bind MA, Béjot Y, Morel O, Argacha JF (2017). Cardiovascular effects of air pollution. Arch Cardiovasc Dis.110(11):634-642.

Diego GD , Juliano C, Luiz CM, Gabriel GC, and Raphael MR. (2017). Relationship between Resting Heart Rate, Blood Pressure and Pulse Pressure in Adolescents. Arq Bras Cardiol; 108(5): 405-410.

Farrow A (1997). Time spent in the home by different family members. J. Environ. Technol. 18:605-614

Karlqvist L, Leijon O, Härenstam A (2003) Physical demands in working life and individual physical capacity. Eur J Appl Physiol 89: 536-547.

Korshøj M, Krustrup P, Jespersen T, Søgaard K, Skotte JH, Holtermann A. (2013). A 24-h assessment of physical activity and cardiorespiratory fitness among female hospital cleaners: a pilot study. Ergonomics. 56:935-943.

Krause N, Brand RJ, Arah OA, Kauhanen J (2015) Occupational physical activity and 20-year incidence of acute myocardial infarction: results from the Kuopio Ischemic Heart Disease Risk Factor Study. Scand J Work Environ Health 41: 124-139.
Lelieveld J, Evans JS, Fnais M, Giannadaki D, Pozzer A (2015). The contribution of outdoor air pollution sources to premature mortality on a global scale. Nature. 17; 525(7569):367-71.

Li Loerbroks JA, Coic PJ. (2013). Physical activity and risk of cardiovascular disease: what does the new epidemiological evidence show? Curr. Opin. Cardiol. ; 28(5):575-583.

Miller KA, Siscovick DS, Sheppard L. (2007). Longterm expo-sure to air pollution and incidence of cardiovascular events in women. $N$ Engl $\mathrm{J} \mathrm{Med;}$ 356:447-58.

WHO (2004). Exposure to air pollution: a major public health concern

Zöller B, Li X, Sundquist J, Sundquist K (2012) Socioeconomic and occupational risk factors for venous thromboembolism in Sweden: a nationwide epidemiological study. Thromb Res 129: 577-582. 